\title{
TRADIÇÕES ALIMENTARES E COMIDAS EMBLEMÁTICAS
}

\author{
Maria Eunice Maciel ${ }^{1}$ \\ Evelize Moreira $^{2}$
}

\section{Introdução}

Desde alguns anos a alimentação tem tido um destaque especial tanto como área de estudos especializados quanto preocupação da população em geral. A quantidade de livros, revistas e programas das mais diversas mídias mostram a força do tema e são várias as discussões e embates que ocorrem tanto no campo acadêmico quanto no que concerne ao senso comum.

Dentro do campo acadêmico, várias são as discussões e controvérsias em relação aos elementos alimentares, como é possível lembrar no caso do ovo que pergunta-se se pode ser indicado em dietas para quem tem problemas de colesterol ou não (ou, costumeiramente, "faz mal ou não?"). Demonizado em um primeiro momento, foi absolvido posteriormente sendo hoje permitido com moderação. Outro caso exemplar é o que concerne às gorduras. Prescritas como vilãs foram sendo absolvidas paulatinamente; primeiro as que fazem parte de determinadas dietas, tais como os azeites de Oliva, depois, algumas específicas e agora até mesmo as gorduras de origem animal estão sendo permitidas, sempre com o conselho de consumir com moderação. Vilãs mesmo, permanecem as gorduras hidrogenadas, as chamadas "gorduras trans" tal como a margarina que no passado chegou a ser a heroína das dietas para idosos e pessoas com problemas cardíacos e/ou com colesterol alto, entre outros.

Em um mundo globalizado, um grande número de elementos tradicionais de certos povos foram elegidos como panaceias e indicados para todos em geral, independente de onde nasceram, moram e de quais os seus hábitos culturais e, dentro desses, os alimentares. Temos como exemplo a quinoa, a linhaça, a chia, o coco e tantos outros. A questão não é se "faz bem ou não" mas como são apreendidos e elaborados pelas pessoas que buscam saúde e, principalmente, o embelezamento estético conforme

\footnotetext{
${ }^{1}$ UFRGS, Brasil. Email: mariaeunicemaciel@gmail.com

ORCID id: https://orcid.org/0000-0002-0000-1287

${ }^{2}$ UFRGS, Brasil. Email: evelize.moreira@gmail.com

ORCID id: https://orcid.org/0000-0002-5934-062X
} 
os padrões do momento, salientando-se o fato de que constituem-se em um grande mercado em expansão.

A Obesidade passou a ser um problema de saúde global. Se antes a Fome era o grande fantasma que rondava a humanidade, agora, os mais diversos organismos relacionados à saúde, a começar pela Organização Mundial da Saúde (OMS), voltam-se para a obesidade e suas decorrências. O discurso, quando adotado e elaborado pela população em gera, é fugidio. Embora se constitua procurando focar na saúde uma observação mais atenta mostra o que existe abaixo deste, é uma grande vontade e desejo de entrar em um determinado padrão (ver, entre outros, Jeronimo: 2019).

As mais variadas dietas surgem a cada ano: a "Mediterrânea", a "Paleolítica", a "Ração Humana", a do "Dr. Atkins" (com todas as suas transformações posteriores, a que corta carboidratos), o "Jejum", o "Jejum Intermitente" e tantas outras com alguma, nenhuma, ou certa propriedade e eficácia, conforme os especialistas na área biológica da Alimentação.

É importante salientar que esta situação relaciona-se ao crescimento substancial do mercado de alimentos para atender a estas demandas, não apenas das novas dietas mas de um novo estilo de vida que se instaura nas grandes cidades, modelo que tem o mundo ocidental anglo - europeu como origem mas que se dissemina no meio urbano dos mais diversos países. Podemos ver tal fato na expansão dos chamados Alimentos Light e Diet, assim como os Low Carb ou Law Fat (em grande medida uma certa resposta da indústria alimentícia às questões relativas ao "saudável") como também as transformações no consumo de comidas prontas tais como os Delivery (tele entregas), os Fast-Food (comidas rápidas), os Big Food (produtos de indústrias transnacionais de alimentos processados e ultra processados) e outros.

Isso também sem falarmos de Segurança Alimentar e/ou Food Security, cujo conceito pode passar de segurança em ter o que comer até o alimento seguro. Enfim, queremos mostrar, em grandes linhas, como o tema da Alimentação adquire hoje uma força muito grande e assim como é importante o seu estudo.

No entanto, cabe refletir sobre o que entendemos como alimentação. Podemos pensar em três dimensões: a Nutricional (que garante a sobrevivência viva dos seres vivos) e a Alimentação (ingesta de alimentos considerando tanto o âmbito biológico quanto o nutricional) e a Comida (a alimentação culturalizada, ou seja, a alimentação 
humana em sua dimensão cultural). Claro que é uma divisão passível de inúmeras críticas mas, dentro do contexto atual, serve para delimitar o campo de Estudos.

É dentro deste quadro que emergem os estudos de Antropologia da Alimentação que trazem aportes significativos para a discussão sobre Alimentação. Tema muito apreciado pelos antropólogos desde o início da disciplina, podemos Malinowski e o inhame das ilhas Trobiand ou o Potlach dos nativos da Columbia Ocidental, somente para citar alguns. Lembramos também as reflexões de Lévi-Strauss relativas à Natureza e Cultura em o Cru e o Cozido, Do Mel as Cinzas, A Origem das Maneiras à Mesa, o Triangulo Culinário e outras tantas nas quais podemos aplicar sua célebre frase, são "boas para pensar".

Embora não fosse um tema específico tal como os Mitos ou o Parentesco e muitas vezes fizesse parte de divisões da disciplina tal como a Antropologia Econômica, a partir da discípula da Malinowski, Audrey Richards, aos poucos foi se estabelecendo e hoje existe um grande número de trabalhos que se reivindicam desta linha de pesquisa, em especial produzindo etnografias sobre a Alimentação / Comida e havendo mesmo organizações internacionais para reuni-los tais quais o ICAF (International Commission in Anthropology of Food), comissão permanente do IUAES (International Union Anthropologycal and Ethnological Sciences).

Entre as preocupações relativas ao momento atual, muitas se voltam às questões identitárias tanto em função das transformações em que os sistemas (produção e consumo dos alimentos) e as estruturas alimentares (hábitos e habitus, manifestações e cosmologia alimentar, prescrições e proscrições) tem modificado os estilos de vida tradicionais quanto às grandes migrações que estão ocorrendo onde milhares de pessoas deixam suas comunidades originais estabelecendo-se em locais com estruturas socioculturais muito diferentes das suas anteriores necessitando uma determinada forma de adaptação.

Nestes casos, a Antropologia tem muito a oferecer pois, principalmente através da etnografia, descortina as vivências cotidianas, o dito e o não - dito, os significados e as relações estabelecidas entre grupos, interna ou externamente. E é neste sentido que segue este trabalho.

\section{A construção de uma "cozinha"}


Um dos aspectos mais significativos que envolve o comer ou o ato alimentar ou ato culinário (PERLÉS,1979) é o que trata da construção de um conjunto de hábitos, maneiras e percepções que é ou quer ser associado a um determinado grupo social, expresso por determinados pratos que formariam aquilo que é chamado de "Cozinha".

No processo de construção do que é chamada de "Cozinha", seja ela local, regional, nacional, internacional, transnacional, ligada às etnias ou classes sociais, determinados elementos da cultura alimentar são escolhidos para representar o grupo. São escolhidos justamente aqueles que são percebidos como os mais "característicos" (próprios de), tornando-se assim, emblemáticos e formando uma "cozinha emblemática" que se quer diferenciada, única, capaz de agir no reconhecimento do grupo por outros e, internamente, operando com um sentimento, o de pertencimento.

Isso remete, diretamente, à discussão sobre a noção de identidade, a qual é, aqui, usada a partir do conceito de identidade proposto por Lévi-Strauss em um seminário dirigido por ele mesmo:

Dans cette hypothèse, vers quoi mous orientons - nous pour formuler la notion d'identitè et resoudre le problème? Ce serait dans la voie opposèe à celle d'um substancialisme dynamique; ce serait em considèrant que l'identité est une sorte de foyer virtuel auquel il nous est indispensable de nous référer pour expliquer um certain nombre de choses, mais sans qu'il ait jamais d'existence réelle. Et la solution de l'antinomie dont je suis partie, et dont on fait procès à l'ethnogie em lui disant: "Vous voulez étudier des sociétés complètement diferentes, mais, pour les étudier, vous les réduisez à l'identité", cette solution n'existe que dans l'effort des sciences humaines pour dépasser cette notion d'identité, et voir que son existence est purement théorique; celle d'une limiteà quoi ne correspond em réalité aucune expérience. (Lévi-Strauss, 1977: 332)

Assim, procura-se o processo de identificação, de construção cujo resultado é uma dada identidade, vista como um "ponto de referência", importante mas não fixo nem cristalizado podendo ser refeito a todo momento conforme as vivências coletivas do grupo que a constrói e a opera.

Muito frequentemente, neste processo, os elementos que cumprem um papel de marcadores de diferenças (ou marcadores de identidade), os sinais diacríticos identificatórios, no caso os pratos, itens (tal como determinado tipo de alimento ou tempero) ou maneira de fazer ou comer são buscados no passado do grupo, em um 
modo de vida em vias de desaparecimento, senão já desaparecido, ou seja, aquilo que é conhecido geralmente como Tradição (e, dentro delas, as tradições alimentares), tornando-se assim um referencial ao qual o grupo se volta e utiliza para se definir perante os outros.

No entanto, o uso do termo tradição requer alguns cuidados, pois ele implica em uma relação um tanto complicada entre o passado e o presente ${ }^{3}$. É frequente vê-la como resíduo de um passado que teria chegado até o presente sendo mantida por determinados grupos (em geral, o assim chamado "povo", termo ambíguo e nem sempre sinônimo de classes populares), chamados também de "guardiões da memória" os quais se tornariam objeto de estudo e pesquisa como forma de "resgatar" ou "recuperar" esta memória.

Essa concepção está ancorada na ideia da existência de uma sociedade "tradicional" (em geral, camponesa, mas não unicamente), capaz de manter uma "pureza", não contaminada pela contemporaneidade, ou seja, pelo presente. Essa "pureza" se traduziria como "autenticidade" e, dessa forma, seria capaz de revelar a "identidade" de um povo naquilo que ele teria de mais próprio e, portanto, mais "verdadeiro". Isso, guardadas as proporções, faz lembrar a noção de "poluição" de Mary Douglas está associada à ideia de perigo, constituindo-se em uma analogia para expressar uma ordem social e onde coisas vindas de fora, transcendendo fronteiras e classificações são “sujas” e perigosas (Douglas, 1976).

Essa perspectiva remete à procura do exótico e / ou do arcaico, em suma, daquilo que aparece como "pitoresco" (no sentido de diferente) para servir como expressão de uma identidade. O passado, neste quadro, torna-se uma "garantia de veracidade" e o fator legitimador de um costume ou de uma manifestação cultural, já que é nele que seriam encontradas as tradições e seria ele o manancial de onde são buscados os elementos que vão ser os marcadores que agem no sentido de estabelecer uma diferença, fazendo assim parte de um processo de identificação cujo resultado seria uma dada identidade, usada para o conhecimento e reconhecimento de grupos sociais os mais diversos.

Assim, o critério "antiguidade" é relacionado com "autenticidade", ou seja, quanto mais remoto, mais legítimo se torna. Autêntico, numa dada concepção, se opõe à cópia, ao falso o que, no caso, se reflete numa busca pela "autêntica culinária" exemplo

\footnotetext{
${ }^{3}$ Professora e Mestranda do Programa de Pós - Graduação em Antropologia Social da UFRGS
} 
de saberes e fazeres tidos e reconhecidos como pertencentes a um determinado grupo que dela se reivindica. As "autênticas tradições" implicam nas "verdadeiras tradições" (no exemplo relacionado à alimentação, as tradições culinárias, sejam elas locais como as gaúchas, sejam nacionais, como a italiana e outros tipos de recortes) e nos discursos a elas associados.

Trata-se de uma ótica essencialista dentro da qual a cultura, em todos os seus aspectos, é naturalizada, associada às determinadas formas de ser e fazer que constituíssem a identidade do grupo social a elas agregado fazendo parte de um discurso político (Maciel, 1994), o que inclui a sua comida fazendo.

A ideia que associa as manifestações chamadas de "folclóricas" à existência de tradições populares desaparecidas ou em vias de desaparecimento implica, frequentemente, no que já foi chamado de "espírito de antiquário" (Ortiz, 1992). A coleta e preservação de determinados pratos, ou formas de se alimenta, traduzidos em "receitas" sem que isso seja acompanhado de busca de seu sentido para os sujeitos envolvidos parece ter sido a tônica de muitos estudos nesta.

Frequentemente, o que é chamado de "culinária X" é estudada e difundida por determinados tipos de pesquisadores, geralmente alguém proveniente de outra classe social, com outros valores (embora, na maior parte das vezes, seja proveniente do mesmo território que estuda, muitas vezes o "intelectual local") que vai ao encontro dos "menos favorecidos" (neste caso as chamadas "classes populares" ou camponesas) para estudar sua "cultura", tentando preservá-la de possíveis "deturpações" que o tempo e as mudanças sociais trariam. Pode ocorrer também que este pesquisador seja um membro da comunidade que procura trazer aquilo que considera "sua herança cultural" (o que é frequente no caso de descendentes de imigrantes), o que leva a muitos embates no sentido de qual seria a "verdadeira" ou a "autêntica" culinária de seus antepassados.

No entanto, numerosos são os autores que mostraram como esta "autenticidade" é construída, assim como as tradições nas quais ela se baseia Eric Hobsbawn (Hobsbaw,1984), por exemplo, fazendo uma diferenciação entre tradição, tradição inventada e costume, mostra o quanto tais manifestações são construídas e a que objetivos sua permanência serve.

Se, muitas vezes, tradição é pensada como algo que é recebido do passado e mantém uma permanência no presente, conservando-se de forma a manter uma configuração idêntica ao modelo original, noção esta que pertence ao senso comum mas 
também é utilizada por muitos dos que trabalham com tradição, cultura popular e folclore. Esta noção pode criticada, inicialmente, no sentido de que as manifestações ditas "tradicionais" também têm uma história que inclui mudanças e transformações e que, se elas se mantêm no presente, não é da mesma forma que existiam no passado e, portanto, é outro o seu significado.

A ideia de tradição como sobrevivência, como algo cristalizado no tempo e no espaço faz com que se perca justamente a dinâmica e o sentido de determinada manifestação cultural. Lévi-Strauss, falando sobre os rituais de Natal assim coloca:

As explicações por sobrevivência são sempre incompletas; porque os costumes não desaparecem nem sobrevivem sem razão. Quando eles subsistem, a causa se encontra menos numa viscosidade histórica do que na permanência de uma função que a análise do presente deve permitir a desvendar. (Lévi-Strauss apud Belmont s/d).

Fundamental, neste trecho, é a ideia do presente como a referência que faz com que tal costume exista, não por que tenha escapado do desaparecimento, um resíduo anacrônico do passado que se mantém por sua "bizarrice", mas que existe no presente por possuir um determinado significado para os homens do presente.

J. Pouillon, outro autor que trabalha a noção de tradição, diz que "não se trata de colocar o presente sobre o passado mas de encontrar neste o esboço de soluções que nós acreditamos justas hoje não porque elas foram pensadas ontem mas porque nós as pensamos agora" (Pouillon apud Lenclud, 1987: 118).

Comentando esta afirmação, G. Lenclud conclui que a tradição "não é (ou não é necessariamente) aquilo que sempre foi, ela é aquilo que nós a fazemos ser". Procurando definir tradição, Lenclud a percebe não como um produto do passado recebido passivamente pelo presente, mas como um "ponto de vista", uma interpretação deste passado (Lenclud, 1987: 118)

Desta forma, para diversos autores, a tradição é vista através do caminho inverso isto é, ela adquire significado hoje para os homens de hoje ou, como diz Ortega y Gasset "a tradição é uma colaboração que nós pedimos ao nosso passado para resolver nossos problemas atuais" (Ortega y Gasset apud Zunthor, 1988: 105).

Sendo a cultura algo dinâmico, ou seja, está sempre em movimento, transformando-se constantemente, os portadores de uma "cultura tradicional" estão 
sempre recriando essa cultura e seus elementos (como seus saberes, suas crenças, seus valores), ao mesmo tempo em que os reproduzem mediante canais coletivos, comunitários e familiares e, recorrentemente, como ocorre no momento atual, divulgados pelos meios de comunicação. A cultura é, assim, vista como uma coisa viva, em permanente mutação, em que práticas e manifestações culturais são combinadas, apropriadas e re - semantizadas e assim não podendo ser reduzida, no caso da cultura alimentar, a uma lista de pratos ou maneiras alimentares.

Quando a tradição passa a ser usada como um referencial, fazendo parte do processo de construção identitário podemos pensar que a Tradição é um certo tipo de reconstrução da memória, incorporando esquecimento e lembrança. E opera na construção identitária construindo emblemas, que servem para o conhecimento e reconhecimento do grupo.

A etnografia proporciona a visão de como este processo é feito. Através dela, é possível ver-se como Hábitos (e Habitus) alimentares se conjugam com Tradições alimentares construindo pontos de referência que norteiam as vivências das pessoas.

Trabalhar com grupos de migrantes que procuram manter suas maneiras de viver em uma situação de diáspora abre perspectivas para vislumbrarmos e compreendermos as vivências deste grupo.

Desta forma, em grupos migrantes, a alimentação cumpre um papel fundamental seja no cotidiano, trazendo maneiras de comer as quais estão habituados, fazendo parte de suas vivências cotidianas, em especial com a família quanto na manutenção de laços com suas origens e com seus compatriotas. Mais ainda, a utilização de sua cozinha, assim como dos pratos emblemáticos, serve como uma ponte para as relações com os locais, não apenas se "apresentando" através da Comida mas introduzindo-os em seu universo cultural, tornando-se, assim, uma forma de criar e/ ou reforçar laços. 


\section{Ceebu Jën, o prato emblema dos senegaleses}

Trataremos aqui do Ceebu Jën, considerado como o prato emblema que representa os senegaleses, segundo eles mesmos. Tanto em campo quanto em várias referências sobre a cozinha senegalesa e seus chamados pratos típicos, o Ceebu Jën (ou Thiep) é o mais amplamente citado e conhecido, além de consumido. Sendo um prato emblemático da cultura senegalesa, foi ele o apresentado em uma comemoração, em Porto Alegre, particularmente importante para o grupo, o Festival de Arte e Cultura Senegalesa, promovido pela Associação Senegalesa local (que congrega os senegaleses que moram na cidade, todos da etnia wolof) que buscava apresentar ao público tudo o que de mais típico se tem no Senegal e que permitiu uma observação a partir da partilha da feitura e do consumo do mesmo ${ }^{4}$.

A constituição de uma cozinha típica e implica em pratos em que as práticas da cozinha se associam ao pertencimento de um grupo. O prato típico nem sempre é o mais comido diariamente por um grupo, ou em uma região, mas é selecionado como emblema alimentar e representa o modo como as pessoas gostariam de ser reconhecidas. "O emblema como figura simbólica destinada a representar um grupo, faz parte de um discurso que expressa um pertencimento e, assim, uma identidade.” (Maciel, 2005:50)

Segundo a tradição dos griôs, mestres narradores africanos que fazem parte de várias culturas, as origens do Ceebu Jën se conectam a uma mulher chamada Penda Mbaye, da cidade de Saint-Louis, a capital colonial do Senegal. Conta-se que Mbaye era cozinheira na casa do governador da colônia na virada do século XIX e criou o prato unindo o peixe fresco, abundante na costa da África Ocidental, com o arroz que começava a ser importado de países asiáticos. Além disso, ela acrescentou um purê de tomate ao cozido, o que segundo a história, agradou ao paladar dos superiores do governo. O prato, posteriormente, se espalhou por todo o Senegal e países vizinhos como a Costa do Marfim e Guiné, onde é conhecido como "arroz de gordura", ou "arroz senegalês". É comum ainda hoje, no Senegal, chamarem o prato de Ceebu Jën Penda Mbaye, em homenagem a sua criadora.

\footnotetext{
${ }^{4}$ Os estudos sobre Senegaleses em Porto Alegre faz parte da Dissertação de Mestrado de Evelize Moreira intitulada "Comida de Teranga: A migração senegalesa à mesa", orientada pela professora Maria Eunice Maciel.
} 
Para o chef senegalês Pierre Thiam ${ }^{5}$, o Ceebu Jën não recebe justiça em seu nome. Em wolof significa simplesmente peixe com arroz, no entanto, a sua forma de preparo, e temperos, faz com que o prato seja muito mais do que isso. O Ceebu Jën pode ser visto como a própria materialização da teranga, uma noção corrente nessa parte da África e fundamental e estruturante para a sociedade wolof relacionada à identidade dos senegaleses.

O Senegal é conhecido pelos senegaleses e visitantes como a terra de teranga, constituindo-se, assim, símbolo da cultura senegalesa em diferentes grupos étnicos, classes sociais e crenças religiosas do país., sendo frequente ouvir-se dos senegaleses a frase "somos um povo de Teranga, muita Teranga".

A Teranga pode ser traduzida como uma forma de hospitalidade, mas é muito mais do que isso. É uma forma de estabelecimento de relações sociais transmitindo um padrão moral e social que é incorporado em ações e falas dos indivíduos, a partir de uma construção de símbolo central de nacionalismo e identidade senegaleses.

Para o chef senegalês Pierre Thiam, Teranga é a palavra que simboliza o melhor do Senegal. Teranga seria o modo como você trata o seu próximo, todos são como convidados. Poder-se-ia, a partir de Thiam, considerar que há três ações que poderiam explicar a Teranga de uma forma mais inteligível:

I.Você precisa tratar o próximo com muito respeito.

II.Você precisa oferecer tudo o que tem.

III. Você deve convidar o seu próximo para se sentar com você ao redor de sua bacia de comida.

Segundo Ryley (2016), Teranga, no sentido de hospitalidade expressaria os principais aspectos da socialidade senegalesa. Hospedar, visitar, dar presentes, ser aberto e generoso para com os outros, assim como a maneira pela qual esses atos são conduzidos e as intenções por trás deles, é o que criaria a estrutura que comporta as relações sociais da sociedade senegalesa.

Ela é coletiva e individual ao mesmo tempo pois, além de fazer parte do discurso identitário Senegalês, a Teranga pode ser vista como uma virtude de um indivíduo, aquele que sabe melhor acolher os hóspedes com generosidade e cordialidade (Sylla. 1987). A criação de reputações positivas por meio da participação em cerimônias é crucial para o acesso de uma pessoa a recursos e a ajuda de familiares e amigos

${ }^{5}$ https://www.splendidtable.org/story/chef-pierre-thiam-teranga-is-the-word-that-symbolizes-senegal-thebest 
É na Alimentação, transformada em Comida, que a Teranga pode se expressar e é no Ceebu Jën, prato emblemático senegalês, que é reconhecida.

O Ceebu Jën é forte e intenso. É cozido aos poucos e o defumado do peixe (quando não é o peixe fresco) toma o sabor do prato. Os legumes cozidos vêm para suavizar um pouco os temperos.

O Ceebu Jën comido na privacidade das moradias dos senegaleses locais é consumido segundo suas tradições originais. Come-se de uma bacia de metal posta sobre um tapete de oração (essencial em uma casa muçulmana) onde os comensais sentam-se ao redor. Todos comem com a mão, podendo os convidados não senegaleses comerem em pratos usando garfo e faca que são oferecidos pelos anfitriões, mas comer com as mãos, servindo-se todos do mesmo recipiente, é uma coisa importante na partilha da comida sendo ensinado às crianças.

O sabor da pimenta é intenso. Os presentes à “mesa”, dependendo da intimidade com os convidados brasileiros, podem mesmo rirem-se deles e de suas reações ao experimentarem o prato, dada a quantidade de pimenta. "Come cenoura amor", dizia Absa, a anfitriã nesta ocasião Os legumes, em grande parte das vezes, são utilizados para neutralizar o sabor da pimenta, quando muito forte.

A "grandeza" do Ceebu jën, é construída a partir do seu preparo. Realmente, se pararmos para olhar superficialmente para o prato, vemos arroz com peixe e alguns legumes. No entanto, seu preparo é minucioso e demorado.

Seus ingredientes básicos são arroz, peixe, cenoura, repolho, berinjela, tomate, pimentões, cebola, alho, pimentas de diversos tipos vermelhas e pretas e, algumas vezes, se acrescenta também peixe seco defumado. Os tomates, pimentões, cebolas, salsa e pimentas são batidos no liquidificador e formam uma base de molho para ser refogado. Este refogado apimentado é base para grande parte dos pratos principais e lembra, em certa medida, um sofrito espanhol.

A primeira etapa é o preparo do peixe. O peixe escolhido para o dia do Festival Senegalês foi uma Corvina sendo que o critério de escolha foi o preço. Segundo informações, no Senegal cozinha-se com o peixe que estiver mais fresco e com o melhor preço também, não havendo nenhuma obrigatoriedade de um tipo especial de pescado. De fato, quando no Brasil, os migrantes encontraram peixes diferentes dos utilizados no Senegal, mas isso não acarretou em problemas, para eles, quando da 
feitura do prato. Os peixes para a festa em questão haviam sido recém comprados no Mercado Público de Porto Alegre, sendo frescos.

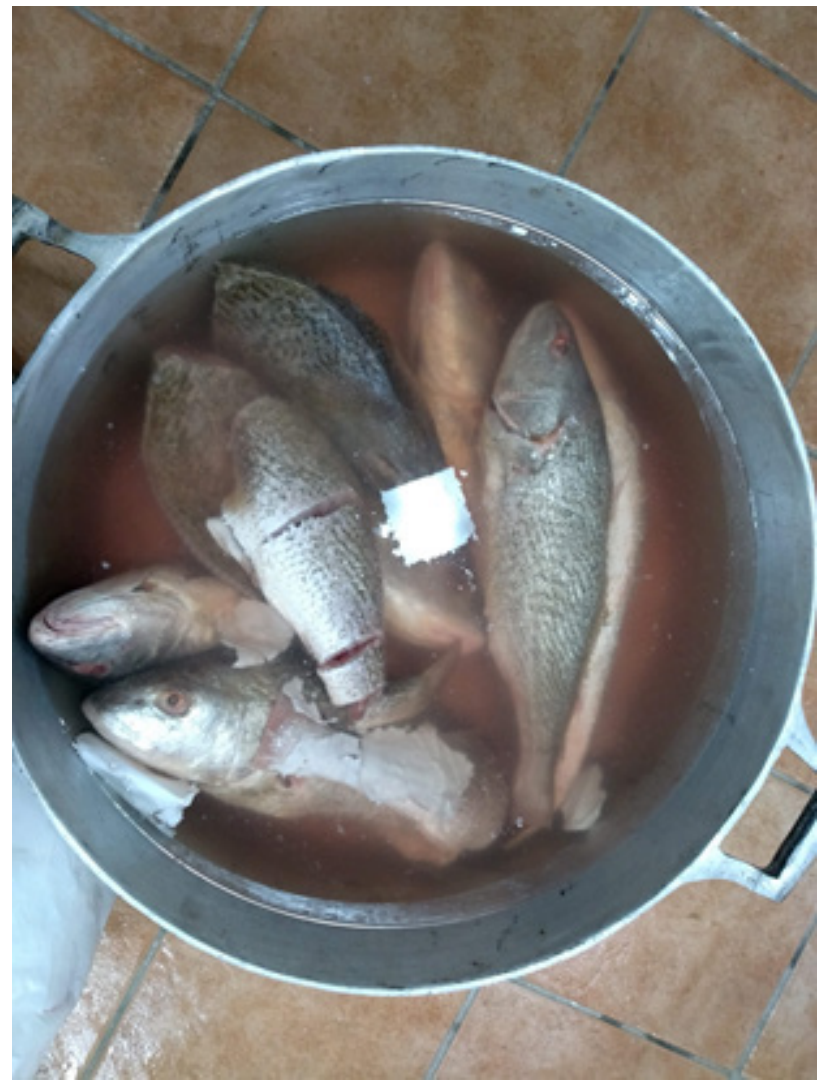

1- Peparando o Ceebu Jën. Foto Evelize Moreira.

Após desembrulhá-los e descamá-los, a cozinheira, Coumba, os colocou em uma panela com água. Enquanto isso, várias pessoas preparavam os legumes: descascavam cebolas, batata doce e limpavam os repolhos.

O peixe foi cortado, então, em pedaços e temperado com tempero pronto (industrializado). Depois, levou-se o peixe ao lume para ser frito em óleo de soja. Após ser frito, o peixe foi retirado da gordura e colocado em uma bacia, onde ficou por uma noite inteira.

Apenas no outo dia, o dia da festa, é que o arroz pode ser preparado. Primeiro colocou-se o óleo para esquentar e depois o molho apimentado para refogar, sendo que os ingredientes do molho foram batidos no liquidificador anteriormente e depois e depois jogados na panela. Dois dos homens alternavam a vigia das panelas. Após um tempo fritando esse preparo, colocou-se muita água quente e um pouco mais de molho de tomate, molho este que era extrato de tomate em lata. Todo este molho, quando incorporado a água torna-se um caldo grosso e perfumado. 


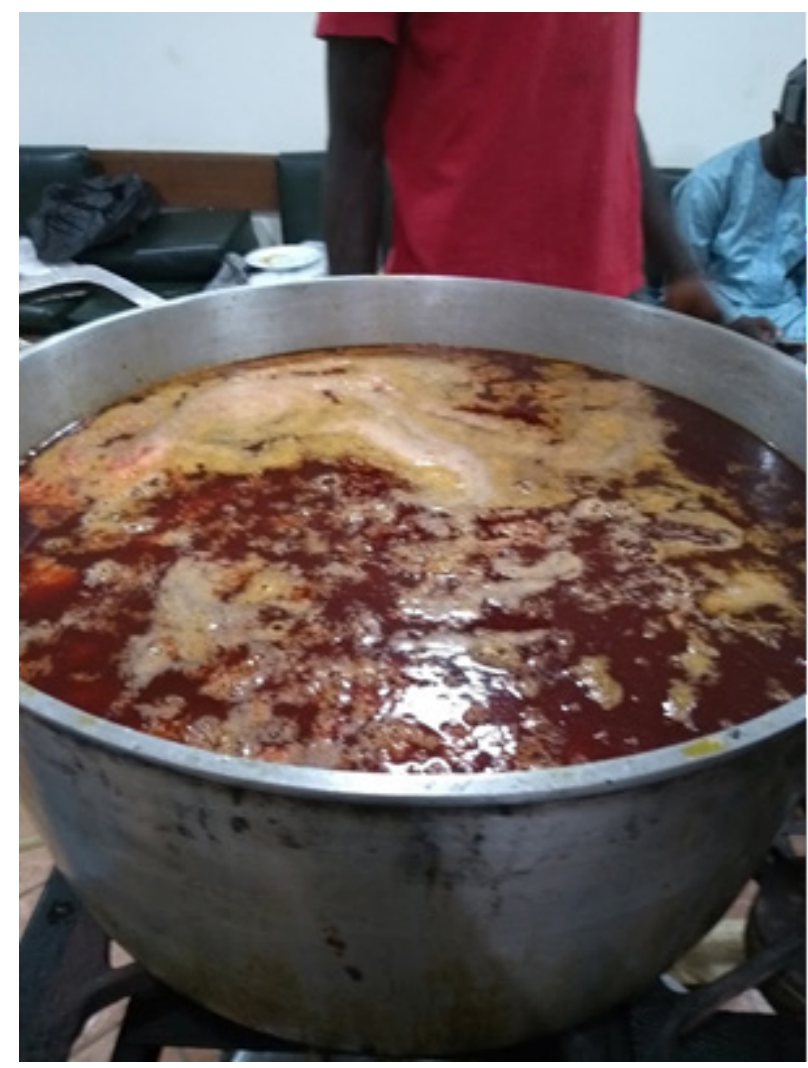

2 - Mesclando sabores. Foto Evelize Moreira.

Apenas depois de muito bem infusionado, para mesclar os sabores, é que se acrescenta o arroz branco, as batatas-doces e o repolho. O tempo todo um dos homens mexia a panela para que o arroz não se queimasse ou acumulasse ao fundo da panela. Também era regulado o tempero e teor de pimenta. O peixe foi incorporado por último e o arroz cozinhou mais um tempo para fixar o sabor do peixe, um pouco fermentado. Para servir, os legumes foram separados dos pedaços de peixe nas bacias, para que fosse mais fácil montar os pratos. 


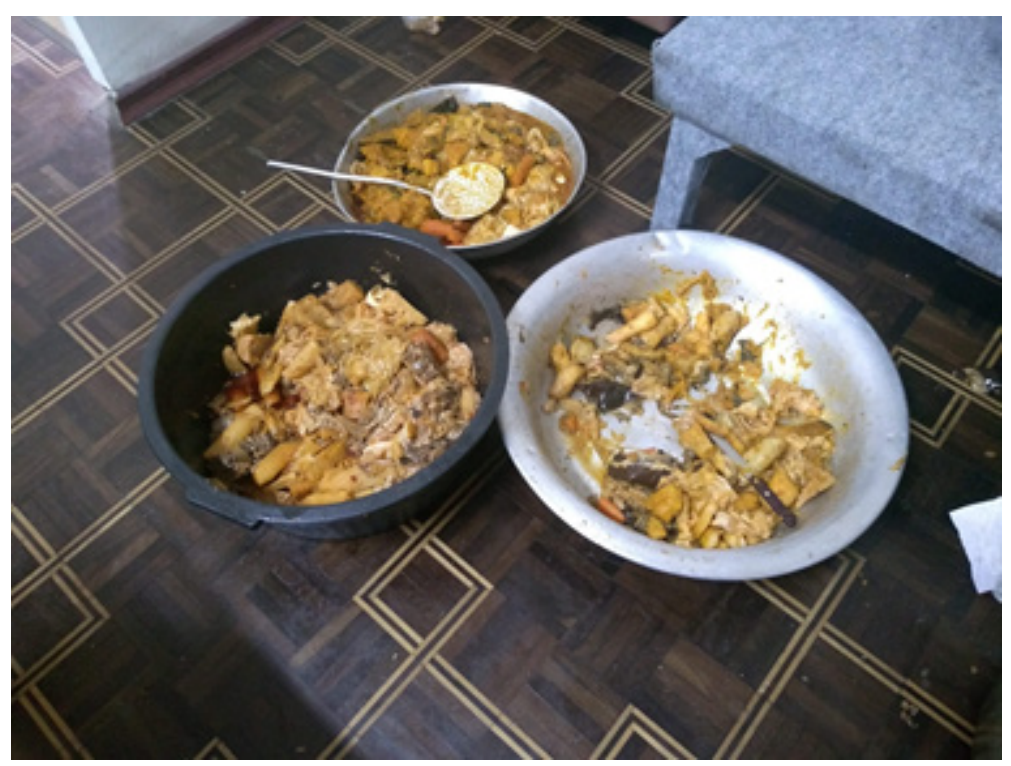

3 - Servindo a Comida. Foto Evelize Moreira.

Como se tratava de um festival, contando com convidados não senegaleses, a pimenta foi moderada assim como também foi servido em pratos para os que assim o desejassem. Mas a comida era farta, muito farta. Deveria dar para todos se servirem e repetirem, a possibilidade de ficarem com fome era impensável.

O fato de ser um cozido e não um assado é significativo. Lembra as palavras de Lévi-Strauss para quem o assado é aristocrático e o cozido é democrático (Lévi-Strauss. 2006). Sim, ao cozinhar, ao se adicionar água, torna-se o prato maior, capaz de alimentar mais pessoas. No Brasil, é conhecida a frase "botar mais água no feijão" para atender a um número maior de pessoas. Embora o Ceebu jën não tenha sido criado em situação de pobreza, ao contrário, nascido da cozinha da casa do governador colonial, poderia ser vista como expressão de um hábito trazido pelos colonizadores ou algo pertencente a estes ou criado só para estes enfim, identificado com o colonizador e adotado pela população em geral. Mas não parece ser este o caso.

O Ceebu Jën, não parece se enquadrar neste caso. Embora criado para um representante do colonialismo, é feito com peixe, arroz, legumes e temperos, elementos cotidianos, de fácil aquisição na região, não sendo considerados nem sofisticados nem luxuosos e fazendo com que o prato em si não ganhe estas classificações. Ganha, sim, um caráter de emblema, associado a uma determinada região e uma história particular ao grupo do qual emerge e dentro do qual adquire significado. 
Trata-se de um prato emblemático consumido em festas tanto grandes, coletivas e comunitárias quanto as pequenas, íntimas e familiares. É um ponto de referência ao grupo de migrantes - são aqueles que comem este prato, o qual faz parte de seus hábitos e de sua história - sua identidade. Cumpre assim, um papel agregador no sentido da sociabilidade do grupo, agregando e identificando-o, agindo no sentido de seu reconhecimento coletivo.

Mas na identificação do grupo através da comida, a Teranga tem um papel significativo nas percepções sobre si mesmo e sobre o prato em si. Através da comida e, em especial, deste prato, é possível expressar sua capacidade ou medida de Teranga ou mesmo de exercitá-la. Para o grupo, a sociabilidade via Teranga é uma forma estruturante de sua vida social, sendo a partilha, em especial a partilha do alimento e da oferta de alimento algo fundamental na sua percepção e suas representações sociais, contidas em seu discurso e em sua ação mostrando comportamentos, valores e maneiras.

Outras festividades marcando datas importantes do grupo Senegalês tal como o Magal Touba (celebração religiosa e política ao mesmo tempo) ou um "batizado" (ritual de nomeação da criança, anterior ao islamismo e existente até hoje) e outros que são também momentos de mostrar sua culinária emblemática mas, também e principalmente, a Teranga, a hospitalidade mas que significa também a doação, de si, que mesmo em dificuldades financeiras procurou trazer o seu melhor, de seu trabalho e de sua pessoa individual mas também coletiva, sua persona senegalesa. 


\section{REFERÊNCIAS}

BELMONT, Nicole. Arnold Van Gennep - créateur de l'ethnographie française. Paris, Petite Bibliotèque Payot.

DOUGLAS, Mary. Pureza e Perigo. São Paulo, Perspectiva, 1976.

HOBSBAWM, Eric e RANGER, Terence. A Invenção das Tradições. RJ, Editora Paz e Terra, 1984.

LENCLUD, Gérard."La tradition n'est plus ce qu'elle était..."in Terrain ${ }^{\circ} 9$, octobre 1987.

LÉVI-STRAUSS, Claude. L'Identité, Paris, Quadridge / PUF 1977.

LÉVI-STRAUSS, Claude. Origem dos Modos à Mesa (Mitológicas v.3). São Paulo, Cosac Nayf, 2006.

MACIEL, M.E. "Os tipos característicos. Região e esteriótipos regionais". Humanas, v.8, n. 1/2, jan/dez, 1995.

MACIEL, M.E. Memória, tradição e tradicionalismo no Rio Grande do Sul. In: BRESCIANI, S.; NAXARA, M. Memória e (res)sentimento: indagações sobre uma questão sensível. Campinas: Unicamp, 2001. p.239-267.

MONTEIRO C.A. "Nutrition and health. The issue is not food, nor nutrients, so much as processing". Invited Commentary. Public Health Nutrition 2009; 12(5):729731.

ORTIZ, R.. Românticos e Folcloristas. SP, Editora Olho d'Água, 1992.

PERLÈS, C.. Les origines de la cuisine. Communications n. 31, 1979, Paris, EHESS, organizao por C. Fischler.

POUILLON, Jean. "Tradition: transmission ou reconstruction" in J. Pouillon, Fétiches sans fétichisme. Paris, Maspero, 1975.

RILEY, Emily J.. Terànga and the art of hospitality: Engendering the nation, politics, and religion in Dakar, Senegal. Michigan State University, 2016.

SYLLA, Assane. 1978. La philosophie morale des Wolofs. Dakar: Sankoré

TODOROV, Tzvetan. Nous et les Autres. Paris, Seuil, 1989.

ZUMTHOR, Paul, "L'oubli et la tradition" in Politiques de l'oubli, Le Genre Humain, Paris, Seuil, octobre 1988.

Entrevista com o chef Senegalês Pierre Thiam:

Thiam https://www.splendidtable.org/story/chef-pierre-thiam-teranga-is-theword-that-symbolizes-senegal-the-best acessada em 15/07/2019 